

Акопджанова М.О.

\title{
ФОРМИРОВАНИЕ СОВРЕМЕННОГО ЗАКОНОДАТЕЛЬСТВА РОССИЙСКОЙ ФЕДЕРАЦИИ ОБ УГОЛОВНОЙ ОТВЕТСТВЕННОСТИ ЗА ПРЕСТУПЛЕНИЯ ПРОТИВ УСТАНОВЛЕННОГО ПОРЯДКА УПЛАТЫ НАЛОГОВ И СБОРОВ
}

\begin{abstract}
Аннотация: Эффективность в борьбе с налоговой преступностью может быть достигнута, в первую очередь, посредством разработки отвечающей существующим реалиям развития и осуществления экономической деятельности законодательной базы. Особенно актуально указанное в отнотении формирования современного законодательства Российской Федерации об уголовной ответственности за преступления против установленного порядка уплаты налогов и сборов. Рассмотрению данного вопроса и посвящена настоящая статья.

Review: In order to efficiently fight tax crimes, it is first of all necessary to develop legislative basis, which would meet the needs of the existing reality of implementation and development of economic activities. The above-mentioned matter is especially topical in regard to the formation of the current legislation of the Russian Federation on criminal responsibility for the crimes against the established order of payment of taxes and levies. This article is devoted to the above-mentioned issue.
\end{abstract}

Ключевые слова: Юриспруденция, формирование, законодательство, тенденция, налоги, сборы, налогоплательщик, преступление, обвиняемый, ответственность

Keywords: jurisprudence, formation, legislation, tendency, taxes, levies, taxpayer, crime, accused, responsibility.

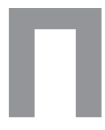

роцесс формирования современного российского законодательства об уголовной ответственности за преступления против установленного порядка уплаты налогов и сборов берёт начало с 13 июня 1996 г., когда был принят первый Уголовный кодекс РФ'. Первоначальная редакция УК РФ 1996 г. включала два состава налоговых преступлений: ст.198 «Уклонение гражданина от уплаты налога», предусматривавшую уголовную ответственность за уклонение гражданина от уплаты налога на доходы в случаях, когда подача декларации является обязательной, либо путём включения в декларацию заведомо искажённых данных о доходах или расходах, совершённое в крупном размере (ч.1) и указанное деяние, совершённое «лицом, ранее судимым за уклонение от уплаты налога, либо совершённое в особо крупном размере» (ч.2), и ст.199 «Уклонение от уплаты налогов с организации», устанавливавшая уголовную ответственность за уклонение от уплаты налогов с организаций путём включения в бухгалтерские документы

${ }^{1}$ См.: Собрание законодательства РФ. - 1996. - №25. - Ст. 2954. заведомо искажённых данных о доходах или расходах либо путём сокрытия других объектов налогообложения, совершённое в крупном размере (ч.1) и указанное деяние, совершённое неоднократно (ч.2). При этом в примечании к ст.198 УК РФ под крупным размером понималась сумма, превышавшая 200 МРОТ, под особо крупным размером сумма, превышавшая 500 МРОТ. Примечание же к ст.199 УК РФ в качестве крупного размера определяло сумму, превышавшую 1000 МРОТ.

Некоторые затруднения в практике применения соответствующих статей об ответственности за налоговые преступления вызывала формулировка диспозиции ст.198 УК РФ. В частности в правоприменительной практике и юридической литературе бытовало мнение о том, что в диспозиции ст.198 речь шла об ответственности за уклонение от уплаты только подоходного налога. В качестве аргумента при этом приводилось употребление слова «налог» в единственном числе 2 . В результате вследствие

\footnotetext{
${ }^{2}$ См., например: Волженкин Б.В. Преступления в сфере экономической деятельности по уголовному праву России / Б.В. Волженкин. - СПб, 2007. - С.668.
} 
введения указанных статей в УК 1996 г. в 1997 г. было зарегистрировано 712 преступлений, квалифицированных по ст.198 и 2001 преступлений - по ст.199 (выявлено лиц, их совершивши - 375 и 1185 соответственно; из них осуждено - 97 и 292 соответственно) $^{3}$.

Серьёзные изменения в регламентацию ответственности за налоговые преступления были внесены Федеральным законом от 25 июня 1998 г. №92-Ф3. Новая редакция ч.1 ст.198 УК предусматривала ответственность за уклонение от уплаты налога путём непредставления декларации о доходах в случаях, когда подача декларации является обязательной, либо иным способом, а равно за уклонение от уплаты страхового взноса в государственные внебюджетные фонды, совершённое в крупном размере. Указание на «иной способ» было внесено с целью устранения ранее существовавших «сомнений» относительно предмета преступления, предусмотренного ч.1 ст.198 УК. Отныне в юридической литературе возникли основания говорить о возможности привлечения физического лица к уголовной ответственности за уклонение от уплаты не только подоходного, но и других налогов, налогоплательщиком по которым первое являлось ${ }^{4}$.

Указания на «иной способ» и «уклонение от уплаты страхового взноса в государственные внебюджетные фонды» было закреплено и в новой редакции ч.1 ст.199 УК. Кроме того, изменения были внесены и в ч.2 ст.199: были закреплены новые квалифицирующие признаки данного преступления - совершение последнего группой лиц по предварительному сговору; лицом, ранее судимым за совершение преступлений, предусмотренных ст.199 и ст.194 (уклонение от уплаты таможенных платежей, взимаемых с организации или физического лица); в особо крупном размере, который определялся суммой неуплаченной налогов и (или) страховых взносов в государственные внебюджетные фонды, превышающей 5000 MPOT.

В то же время, невзирая на позитивную роль указания на «иной способ», последнее способствовало и возникновению некоторые разночтений в понимании способа уклонения. Так, И.И. Кучеров и К.В. Мамилов трактовали «иной способ» уклонения как «обман налоговых органов относительно объектов налогообложения» ${ }^{5}$. Другие исследователи утверждали, что уклонение от уплаты на-

\footnotetext{
${ }^{3}$ Там же- C.664.

${ }^{4}$ См.: Пищулин В.Г. Налоговые преступления: уголовно-правовые и криминологические аспекты: Автореф. дис. ... канд. юрид. наук. - Челябинск, 1999. - С.12; Волженкин Б.В. Указ. соч. - С.670 и др.

${ }^{5}$ См.: Кучеров И.И. Преступления в сфере налогообложения. Научно-практический комментарий у УК РФ / И.И. Кучеров. - М., 1999. - С.43; Кучеров И. Налоги и криминал: Историко-правовой анализ / И.И. Кучеров. - М., 2000; Мамилов К.В. Уголовно-правовое основание уголовной ответственности за уклонение от уплаты налогов: Автореф. дис. ... канд. юрид. наук. - Ижевск, 2002. - С.14.
}

логов может быть совершено и с применением способов, не связанных с обманом (т.е. речь может идти о простой неуплате налогов при фактической возможности сделать это) ${ }^{6}$. Н.А. Лопашенко в качестве «иных способов» называла неоприходование какого-либо имущества, сокрытие ряда сделок, необоснованное внесение индивидуальным предпринимателем в бухгалтерские документы изменений, предоставляющих право на уплату налога по более низкой ставке, неполное бухгалтерское фиксирование торговых и иных операций, перемена места жительства или паспортных данных и т.д.

Ряд исследователей, напротив, отрицал какую-либо целесообразность конкретизации в статье УК способа, посредством которого лицо уклоняется от уплаты налогов, справедливо указывая, что ответственность должна быть установлена за сам факт их умышленной неуплаты ${ }^{8}$.

На практике указание на «иной» способ вызвало сложности в квалификации данных деяний, связанные с подчас расширительным толкованием данной нормы.

Федеральным законом от 25 июня 1998 г. впервые в истории уголовного законодательства России о налоговых преступлениях было введено также специальное основание освобождения от уголовной ответственности лиц, уклонившихся от уплаты налогов. Согласно примечанию 2 к ст.198 УК РФ, введённому указанным Законом, лицо, впервые совершившее преступления, предусмотренные ст.ст. 198, 199 или 194 УК РФ, освобождалось от уголовной ответственности, если оно способствовало раскрытию преступления и полностью возместило причинённый ущерб. В то же время применение данного примечания вызвало некоторые сложности на практике. Как показывает анализ следственной практики того периода, лицо освобождалось от уголовной ответственности независимо от того, кем конкретно был возмещён соответствующий ущерб государству: самим обвиняемым, возглавляемой им организацией либо вообще посторонней организацией. Безусловно, подобное положение дел нарушало не только принцип личной ответственности за содеянное (по сути дела, любое лицо могло возместить по собственному желанию ущерб, причинённый виновным), но и связанное с

\footnotetext{
${ }^{6}$ Например: Сергеев В.И. Объективная сторона - один из важнейших признаков состава налогового преступления / В.И. Сергеев // Российский судья. - 2001. - №8. - С.28; Макаров Д. Г. Теневая экономика и уголовный закон / Д.Г. Макаров. М., 2003.

7 Лопашенко Н.А. Преступления в сфере экономической деятельности. Комментарий к главе 22 УК РФ. - Ростов-на-Дону, 1999. - C.326.

${ }^{8}$ См.: Минская В.C. Налоговая преступность: проблемы законодательства и практики применения / В.С. Минская // Уголовное право. - 2001. - №1 - С.33; Ефимычев П.С. Предмет и пределы доказывания по уголовным делам о налоговых преступлениях / П.С. Ефимычев // Журнал российского права. - 2001. - №9. - С.27 и др.
} 


\section{Право и политика $8(164) \cdot 2013$}

этим нивелирование воспитательной роли и превентивного значения рассматриваемого примечания, к обеспечению которых изначально стремился законодатель при введении данного примечания. По данной причине в связи с неудачной формулировкой нормы, содержавшейся в указанном примечании, указание на специальное основание освобождения от уголовной ответственности за уклонение от уплаты налогов было исключено Федеральным законом от 8 декабря 2003 г №162-Ф3 «О внесении изменений и дополнений в Уголовный кодекс Российской Федерации»9.

Указанным Законом были также изменены наименования и содержание «налоговых» статей УК РФ. Отныне ст.198 «Уклонение от уплаты налогов и (или) сборов с физического лица» и ст.199 «Уклонение от уплаты налогов и (или) сборов с организации» предусматривают уголовную ответственность за указанное уклонение, осуществляемое путём непредставления налоговой декларации или иных документов, представление которых в соответствии с законодательством РФ является обязательным, или путём включения в налоговую декларацию и такие документов заведомо ложных сведений, совершённое в крупном размере (ч.1), и указанное деяние, совершённое в особо крупном размере (ч.2) либо группой лиц по предварительному сговору (ч.2 ст.199 УК). Составы указанных преступлений разграничены по объективной стороне (размерам крупного и особо крупного ущерба, определяемым в примечаниях к названным статьям) и субъекту преступления.

Кроме того, Федеральным законом от 8 декабря 2003 г. №162-Ф3 в Уголовный кодекс РФ были введены ещё две статьи: ст. $199^{1}$ «Неисполнение обязанностей налогового агента», устанавливающая ответственность за «неисполнение в личных интересах обязанностей налогового агента по исчислению, удержанию или перечислению налогов и (или) сборов, подлежащих в соответствии с законодательством Российской Федерации о налогах и сборах исчислению, удержанию у налогоплательщика и перечислению в соответствующий бюджет (внебюджетный фонд), совершённое в крупном размере» (ч.1), и указанное «деяние, совершённое в особо крупном размере» (ч.2); ст. $199^{2}$ «Сокрытие денежных средств либо имущества организации или индивидуального предпринимателя, за счёт которых должно производится взыскание налогов и (или) сборов», в соответствии с которой уголовно наказуемым признаётся сокрытие указанных средств и имущества, за счёт которых должно быть произведено взыскание недоимки по налогам и (или) сборам, совершённое собственником или руководителем организации либо иным лицом, выполняющим управленческие функции в данной организации, или индивидуальным предпринимателем в крупном размере.
В то же время указанным Законом были смягчены и санкции ст.ст. 198 и 199 УК РФ в части наказаний в виде лишения свободы, при одновременном расширении применения штрафов. Отныне санкция ч.1 ст.198 предусматривала в качестве максимального срока наказания лишение свободы на срок до одного года, ч.2 ст.198 - на срок до трёх лет, ч.1 ст.199 - на срок до двух лет, ч.2 ст.199 - на срок до шести лет. Санкция ст. $199^{1}$ также предусматривала максимальное наказание в виде лишения свободы на срок до двух лет (ч.1) и шести лет (ч.2), санкция ст. $199^{2}$ - максимальное наказание в виде лишения свободы до пяти лет. Таким образом, исключив в новой редакции «налоговых» статей УК РФ примечание 2 к ст.198 УК РФ, законодатель фактически распространил на указанные статьи действие ст.75 УК РФ, поскольку отныне указанные преступления (за исключением деяний, предусмотренных ч. 2 ст.199 и ч.2 ст.1991) стали подпадать под категории деяний небольшой и средней тяжести (ст.15 УК РФ). С указанного момента добровольная явка с повинной как признак деятельного раскаяния (ч.1 ст.75 УК РФ) стала одним из условий освобождения лица от уголовной ответственности по данному основанию.

Как показывает анализ диспозиции «налоговых» статей УК РФ в новой редакции, Федеральным законом от 8 декабря 2003 г. №162-Ф3 было также исключено указание на «иной способ» уклонения от уплаты налогов, а способы совершения деяний - унифицированы и конкретизированы. Также были исключены такие квалифицирующие признаки, как совершение преступления лицом, ранее судимым за налоговые преступления, и повторность; установлен принципиально иной порядок определения крупного и особо крупного размеров уклонения от уплаты налогов (сборов), а также крупного (особо) крупного размера ущерба, причинённого в результате неисполнения обязанностей налогового агента.

Однако, к сожалению, невзирая на некоторую «санацию» проблемных моментов действия статей о налоговых преступлениях, указанные преобразования не способствовали снижению налоговой преступности в целом. Так, согласно современной официальной статистике, в 2004 г. было выявлено 17,6 тыс. налоговых преступлений; в 2005 г. - 22,8 тыс.; в 2006 г. - 25,6 тыс.; в 2007 г. - 26,8 тыс.; в 2008 г. - 27,7 тыс. При этом ущерб, причинённый в результате совершения налоговых преступления, исчислялся миллиардами рублей ${ }^{10}$. Следует при этом отметить, что статистические данные, отражающие объём и общественную опасность (социально негативные последствия) налоговой преступности, содержат сведения лишь о небольшой, видимой части «криминального айсберга». Наибольшая же, основная часть налоговых преступлений

${ }^{9}$ См.: СПС «КонсультантПлюс».

${ }^{10}$ CM.: http://www.mvd.ru/stats 
находится вне пределов видимости для сил правопорядка, обладая высокой степенью латентности.

Указанное положение дел обусловило необходимость дальнейших преобразований в сфере уголовно-правовой охраны налоговой системы РФ. Так, Федеральным законом от 29 декабря 2009 г. №383-Ф3 «О внесении изменений в часть первую Налогового кодекса Российской Федерации и отдельные законодательные акты Российской Федерации» в Уголовный кодекс РФ вновь было введено примечание 2 к ст.198, но с существенными изменениями. Согласно новому примечанию, «лицо, впервые совершившее преступление, предусмотренное настоящей статьей, освобождается от уголовной ответственности, если оно полностью уплатило суммы недоимки и соответствующих пеней, а также сумму штрафа в размере, определяемом в соответствии с Налоговым кодексом Российской Федерации». Ныне действующее примечание содержит указание лишь на два условия освобождения: 1) совершение преступления, предусмотренного ст.198 УК, впервые и 2) полная уплата сумм недоимки, пеней и штрафа.

Не менее интересной представляется и законодательная новелла, касающаяся функционирования ст.ст. 199 «Уклонение от уплаты налогов и (или) сборов с организации» и $199^{1}$ УК РФ «Неисполнение обязанностей налогового агента». Так, Законом от 29 декабря 2009 г. №383-Ф3 в Уголовный кодекс РФ было введено примечание 2 к ст.199, согласно которому «Лицо, впервые совершившее преступление, предусмотренное настоящей статьей, а также статьёй $199^{1}$ настоящего Кодекса, освобождается от уголовной ответственности, если этим лицом либо организацией, уклонение от уплаты налогов и (или) сборов с которой вменяется данному лицу, полностью уплачены суммы недоимки и соответствующих пеней, а также сумма штрафа в размере, определяемом в соответствии с Налоговым кодексом Российской Федерации». Как видим, законодательное закрепление получила возможность возмещения лицом ущерба как собственными средствами, так и средствами организации, уклонение от уплаты налогов и (или) сборов с которой вменяется данному лицу. Учитывая специфику экономических преступлений, подобная норма представляется соответствующей принципу личной ответственности (поскольку посторонняя организация уже не может стать непосредственным источником средств, за счёт которых возможно возмещение ущерба, как это было ранее, в период действия редакции УК от 25 июня 1998 г.). Одним словом, в случае, если лицо не в силах возместить причинённый государству ущерб, сделать это можно за счёт средств организации, посредством осуществления деятельности которой соответствующий ущерб был причинён. Указанное соответствует характеру экономической деятельности организации - хозяйствующего субъекта, сопряжённой с извлечением дохода посредством осуществления противоправной деятельности (в данном случае - неправомерной «экономии» на налогах), имеющей баланс, счета и т.д. В то же время примечательным представляется и другое: по сути дела, мы являемся свидетелями постепенного введения в Уголовный кодекс РФ уголовной ответственности юридических лиц. 29 декабря 2009 г. был сделан первый шаг в данном направлении. Но если это будет сделано в отношении организаций - налоговых преступников, то, как представляется, в будущем уголовная ответственность будет введена и в отношении организаций, посредством которых совершались и иные преступления в сфере экономической деятельности. Пока же законодатель предусматривает лишь возможность освобождения виновного лица посредством возмещения причинённого бюджету ущерба организацией, уклонение от уплаты налогов (сборов) с которой соответствующему лицу вменяется.

Кроме того, по сравнению с ранее существовавшими примечаниями к ст.ст.198 и 199 УК РФ, в ныне действующей редакции увеличены размеры ущерба, подпадающего под понятие «крупного» и «особо крупного». Отныне крупным размером в ст.198 признается сумма налогов и (или) сборов, составляющая за период в пределах трех финансовых лет подряд более 600000 рублей, при условии, что доля неуплаченных налогов и (или) сборов превышает 10 \% подлежащих уплате сумм налогов и (или) сборов, либо превышающая 1800000 рублей, а особо крупным размером - сумма, составляющая за период в пределах трех финансовых лет подряд более 3000000 рублей, при условии, что доля неуплаченных налогов и (или) сборов превышает $20 \%$ подлежащих уплате сумм налогов и (или) сборов, либо превышающая 9000000 рублей. Крупным размером в ст.199, а также в статье $199^{1}$ УК РФ признается сумма налогов и (или) сборов, составляющая за период в пределах трех финансовых лет подряд более 2000000 рублей, при условии, что доля неуплаченных налогов и (или) сборов превышает $10 \%$ подлежащих уплате сумм налогов и (или) сборов, либо превышающая 6000000 рублей, а особо крупным размером - сумма, составляющая за период в пределах трех финансовых лет подряд более 10000000 рублей, при условии, что доля неуплаченных налогов и (или) сборов превышает 20 \% подлежащих уплате сумм налогов и (или) сборов, либо превышающая 30000000 рублей.

Таким образом, тенденция развития российского уголовного законодательства о налоговых преступлениях в целом характеризуется смягчением уголовной ответственности, большим, по сравнению с ранними периодами развития, учётом специфики налоговых преступлений как преступлений в сфере экономической деятельности, борьба с которыми должна осуществляться при неуклонном соблюдении принципа соответствия 
DOI: $10.7256 / 1811-9018.2013 .8 .8390$

При цитировании этой статьи сноска на dоі обязательна

\section{Право и политика $8(164) \cdot 2013$}

применяемых мер воздействия характеру и степени общественной опасности данных деяний, т.е. в связи с направленностью последних на незаконное извлечение прибыли посредством неправомерной «экономии» на налогах (сборах), более широкое применение в отношении налоговых преступников и недобросовестных налогоплательщиков в целом получает применение «финансовых» методов воздействия, включающих штрафы как вид наказания и полное возмещение ущерба, причинённого бюджету, как условие освобождения от уголовной ответственности.

\section{Библиография:}

1. Волженкин Б.В. Преступления в сфере экономической деятельности по уголовному праву России / Б.В. Волженкин. - СПб, 2007.

2. Ефимычев П.С. Предмет и пределы доказывания по уголовным делам о налоговых преступлениях / П.С. Ефимычев // Журнал российского права. 2001. - №9.

3. Кучеров И.И. Преступления в сфере налогообложения. Научно-практический комментарий у УК РФ / И.И. Кучеров. - М., 1999.

4. Кучеров И. Налоги и криминал: Историко-правовой анализ / И.И. Кучеров. - М., 2000.

5. Лопашенко Н.А. Преступления в сфере экономической деятельности. Комментарий к главе 22 УК РФ. - Ростов-на-Дону, 1999.

6. Макаров Д. Г. Теневая экономика и уголовный закон / Д.Г. Макаров. М., 2003.

7. Мамилов К.В. Уголовно-правовое основание уголовной ответственности за уклонение от уплаты налогов: Автореф. дис. ... канд. юрид. наук. - Ижевск, 2002.

8. Минская В.С. Налоговая преступность: проблемы законодательства и практики применения / В.С. Минская // Уголовное право. - 2001. - №1.
9. Пищулин В.Г. Налоговые преступления: уголовноправовые и криминологические аспекты: Автореф. дис. ... канд. юрид. наук. - Челябинск, 1999.

10. Сергеев В.И. Объективная сторона - один из важнейших признаков состава налогового преступления / В.И. Сергеев // Российский судья. - 2001. - №8.

\section{References (transliteration):}

1. Volzhenkin B.V. Prestupleniya v sfere ekonomicheskoy deyatel'nosti po ugolovnomu pravu Rossii / B.V. Volzhenkin. - SPb, 2007.

2. Efimychev P.S. Predmet i predely dokazyvaniya po ugolovnym delam o nalogovyh prestupleniyah / P.S. Efimychev // Zhurnal rossiyskogo prava. - 2001. - №9.

3. Kucherov I.I. Prestupleniya v sfere nalogooblozheniya. Nauchno-prakticheskiy kommentariy u UK RF / I.I. Kucherov. - M., 1999.

4. Kucherov I. Nalogi i kriminal: Istoriko-pravovoy analiz / I.I. Kucherov. - M., 2000.

5. Lopashenko N.A. Prestupleniya v sfere ekonomicheskoy deyatel'nosti. Kommentariy k glave 22 UK RF. - Rostovna-Donu, 1999.

6. Makarov D. G. Tenevaya ekonomika i ugolovnyy zakon / D.G. Makarov. M., 2003.

7. Mamilov K.V. Ugolovno-pravovoe osnovanie ugolovnoy otvetstvennosti za uklonenie ot uplaty nalogov: Avtoref. dis. ... kand. yurid. nauk. - Izhevsk, 2002.

8. Minskaya V.S. Nalogovaya prestupnost': problemy zakonodatel'stva i praktiki primeneniya / V.S. Minskaya // Ugolovnoe pravo. - 2001. - №1.

9. Pischulin V.G. Nalogovye prestupleniya: ugolovnopravovye i kriminologicheskie aspekty: Avtoref. dis. ... kand. yurid. nauk. - Chelyabinsk, 1999.

10. Sergeev V.I. Ob'ektivnaya storona-odin iz vazhneyshih priznakov sostava nalogovogo prestupleniya/V.I. Sergeev // Rossiyskiy sud’ya. - 2001. - №8. 